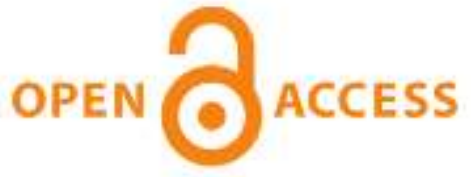

\section{International Journal of Applied Sciences and Biotechnology}

\author{
A Rapid Publishing Journal
}

ISSN 2091-2609

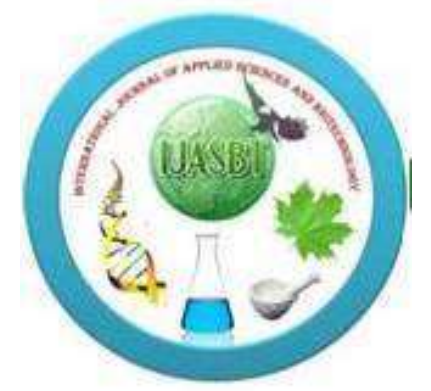

Available online at:

$\frac{\text { http://www.ijasbt.org }}{\&}$

http://www.nepjol.info/index.php/IJASBT/index

\section{Indexing and Abstracting}

CrossRef, Google Scholar, Global Impact Factor, Genamics, Index Copernicus, Directory of Open Access Journals, WorldCat, Electronic Journals Library (EZB), Universitätsbibliothek Leipzig, Hamburg University, UTS (University of Technology, Sydney): Library, International Society of Universal Research in Sciences (EyeSource), Journal Seeker, WZB, Socolar, BioRes, Indian Science, Jadoun Science, Jour-Informatics, Journal Directory, JournalTOCs, Academic Journals Database, Journal Quality Evaluation Report, PDOAJ, Science Central, Journal Impact Factor, NewJour, Open Science Directory, Directory of Research Journals Indexing, Open Access Library, International Impact Factor Services, SciSeek, Cabell's Directories, Scientific Indexing Services, CiteFactor, UniSA Library, InfoBase Index, Infomine, Getinfo, Open Academic Journals Index, HINARI, etc.

\section{CODEN (Chemical Abstract Services, USA): IJASKD}

Vol-2(4) December, 2014

Impact factor*: $\mathbf{1 . 4 2 2}$

Scientific Journal Impact factor $\#$ : 3.419

SEM-Biotech

Index Copernicus Value: $\mathbf{6 . 0 2}$

Publishing

*Impact factor is issued by Universal Impact Factor. Kindly note that this is not the IF of Journal Citation Report (JCR). "Impact factor is issued by SJIF INNO SPACE. 


\title{
ANTIMICROBIAL EFFICACY OF METHANOLIC EXTRACT OF ROOT, CALLUS AND FRUIT EXTRACTS OF MYXOPYRUM SMILACIFOLIUM BLUME
}

\author{
Praveen R.P* and Ashalatha S Nair \\ Department of Botany, University of Kerala, Karyavattom, Thiruvananthapuram \\ *Corresponding author E-mail- Praveen_ker@rediffmail.com
}

\begin{abstract}
The aim of the present study was to compare the antimicrobial efficacy of methanolic extract of root, callus and fruit of Myxopyrum smilacifolium Blume. Antimicrobial activity was tested using agar well diffusion with four bacterial strains viz: Escherechia coli, Enterococcus faecalis, Bacillus subtilis and Staphylococcus aureus of which E. coli alone was gram negative. The fungal strain employed was Candida albicans. Root extracts shown to be effective only against $B$. subtilis. Fruit extracts showed the maximum antimicrobial activity against all the microbial species considered for the current study except against $S$. aureus. Highlight of the present study was the antimicrobial activity of callus extracts.
\end{abstract}

Keywords: Callus; Antibacterial; Antifungal; zone of inhibition.

\section{Introduction}

Since ancient times, people have been exploring the nature particularly plants in search of new drugs. This has resulted in the use of large number of medicinal plants with curative properties to treat various diseases (Verpoorte; 1998).Nearly $80 \%$ of the world's population relies on traditional medicines for primary health care, most of which involve the use of plant extracts (Sandhya et al., 2006). Plant derived chemicals are a promise for it to be used as the active ingredients of modern medicine or as the lead compounds for new drug discovery.

Myxopyrum smilacifolium is a large woody climbing shrub belonging to the family Oleaceae. Its root, stem, leaves are of much medicinally active and is employed in many traditional systems of medicine. The roots are used to treat various diseases like scabies, cough, rheumatism, fever, cuts and wounds. The leaves are astringent, acrid, sweet, thermogenic, anodyne, febrifuge and tonic. They are useful in vitiated conditions of kapha and vata, cough, asthma, rheumatism, cephalalgia, nostalgia, fever, otopathy, neuropathy and cuts and wounds (Warrier; 1996). pharmacokinetic evaluation has been made for the plant and reported for the presence of terpenoids, flavones, anthraquinones, sugars, alkaloids, phenols, tannins, and saponins, antimicrobial study has been carried out in leaves (Gopalakrishnan et al; 2012). Previous studies have shown the presence of triterpenoid ursolic acid in leaves (Sudharmini and Ashalatha; 2008) and the iridoid glycoside myxopyroside (Franzyk; 2001).
Medicinal plants are also a rich source of many antimicrobial agents. They can be used as a substitute for many synthetic antimicrobial agents. An antimicrobial is a compound that kills or inhibits the growth of microbes such as bacteria (antibacterial activity), fungi (antifungal activity).

The present study was carried out to in order to have a comparative study on the antimicrobial activity between the methanolic root, callus and fruit extracts. In order to evaluate the antibacterial efficacy Agar well diffusion method was conducted against four strains viz: $E$ coli, Enterococcus faecalis, Bacillus subtilis and Staphylococcus aureus. Candida albicans was the only fungus used for testing antifungal activity.

\section{Materials and Methods}

Collection and processing of plant material

Fresh plant roots of $M$. smilacifolium were collected from Botanical garden, Dept. of Botany, University of Kerala, Kariavattom. The roots were washed thoroughly with tap water followed by sterile distilled water. Shade dried roots were then crushed to coarse powder and were stored at room temperature in air tight containers.

For callus induction surface sterilized internode explants were first inoculated in MS medium supplemented with $0.1 \%$ 2, 4 Dichlorophenoxy acetic acid (2,4-D) and then sub-cultured on to same medium supplemented with a combination of $0.1 \%$ 2,4-D and $1.0 \%$ Benzyl amino purine (BAP). Four week old callus was collected and dried in hot 
air oven at $50^{\circ} \mathrm{C}$. Dried callus then powdered using mortar and pestle and stored in refrigerator.

Fresh matured fruits collected were washed thoroughly under running tap water, chopped into pieces and dried in shade. It was then crushed with mortar and pestle and stored in refrigerator.

\section{Extraction}

Powdered root, callus and fruit of M.smilacifolium were extracted using methanol in soxhlet apparatus for $12 \mathrm{hrs}$. The extracts were then filtered through Whatmann No.1 filter paper and concentrated using vacuum evaporator. The extract value calculated and then stored in refrigerator for further use.

\section{Antimicrobial activity}

Antimicrobial efficacy of the samples were tested against four bacterial strains and one fungal strain. Agar well diffusion method was employed for both antibacterial and antimicrobial studies.

\section{Agar- well diffusion method}

The principle of this method is that antimicrobials present in the plant extract are allowed to diffuse out into the medium and interact in a plate freshly seeded with the test organisms. The resulting zone of inhibition will be uniformly circular as there will be a confluent lawn of growth. The diameter of zone of inhibition was measured in centimeters. The reagents required and their preparations are as given below.

\section{Muller Hinton Agar Medium}

The medium was prepared by dissolving $33.9 \mathrm{~g}$ of the commercially available Muller Hinton Agar Medium (HiMedia) in $1000 \mathrm{ml}$ of distilled water. The dissolved medium was autoclaved at $15 \mathrm{lbs}$ pressure at $121^{\circ} \mathrm{C}$ for 15 minutes. The autoclaved medium was mixed well and poured onto $100 \mathrm{~mm}$ petriplates $(25-30 \mathrm{ml} /$ plate $)$ while still molten.

\section{Nutrient broth}

One litre of nutrient broth was prepared by dissolving $13 \mathrm{~g}$ of commercially available nutrient medium (HiMedia) in $1000 \mathrm{ml}$ distilled water and boiled to dissolve the medium completely. The medium was dispensed as desired and sterilized by autoclaving at $15 \mathrm{lbs}$ pressure $\left(121^{\circ} \mathrm{C}\right)$ for 15 minutes.

\section{Procedure}

Petriplates containing $20 \mathrm{ml}$ Muller Hinton medium were seeded with $24 \mathrm{~h}$ culture of bacterial strains $E$ coli, Enterococcus faecalis, Bacillus subtilis and Staphylococcus aureus. Wells of approximately $10 \mathrm{~mm}$ was bored using a well cutter and $25 \mu \mathrm{l}, 50 \mu \mathrm{l}$ and $100 \mu \mathrm{l}$ of sample was added to the well. The plates were then incubated at $37^{\circ} \mathrm{C}$ for $24 \mathrm{~h}$. The antibacterial activity was assayed by measuring the diameter of the inhibition zone formed around the well (NCCLS, 1993). Gentamycin, a standard antibacterial agent at a concentration of $20 \mathrm{mg} / \mathrm{ml}$ was used as the positive control.

In order to access the antifungal efficacy of the extracts the minimal inhibitory activity was determined by Agar well diffusion method. Potato Dextrose agar plates were prepared and overnight grown species of fungus such as Candida albicans was swabbed. Wells of approximately 10 $\mathrm{mm}$ was bored using a well cutter and samples of $50 \mu 1$ and $100 \mu 1$ concentration were added, the zone of inhibition was measured after overnight incubation and compared with that of standard antibiotic clotrimazole.

\section{Results}

\section{Antimicrobial activity}

The result of the antimicrobial activity of the extracts are as shown in the Table 1 and 2. Table 1 shows antibacterial and Table 2 shows antifungal activity.

Table 1: Antibacterial activity of root, callus and fruit extracts on various bacteria

\begin{tabular}{|c|c|c|c|c|c|c|}
\hline \multirow{2}{*}{ Method } & \multirow{2}{*}{ Methanolic Extracts } & \multirow{2}{*}{ Volume $(\mu \mathrm{l})$} & \multicolumn{4}{|c|}{ Microorganism/zone of inhibition $(\mathrm{cm})$} \\
\hline & & & EC & $\mathbf{E F}$ & BS & $\mathbf{S A}$ \\
\hline \multirow{10}{*}{$\begin{array}{l}\text { Agar-well } \\
\text { Diffusion } \\
\text { method }\end{array}$} & \multirow{3}{*}{ Root } & 25 & - & - & - & - \\
\hline & & 50 & - & - & $1.1 \pm 0.13$ & - \\
\hline & & 100 & - & - & $1.3 \pm 0.05$ & - \\
\hline & \multirow{3}{*}{ Callus } & 25 & - & - & - & - \\
\hline & & 50 & - & $1.2 \pm 0.19$ & - & - \\
\hline & & 100 & - & $1.4 \pm 0.09$ & $1.2 \pm 0.09$ & $1.0 \pm 0.06$ \\
\hline & \multirow{3}{*}{ Fruit } & 25 & - & $2.7 \pm 0.03$ & $1.5 \pm 0.15$ & - \\
\hline & & 50 & $1.1 \pm 0.12$ & $3.5 \pm 0.07$ & $1.7 \pm 0.04$ & - \\
\hline & & 100 & $1.2 \pm 0.06$ & $3.9 \pm 0.05$ & $1.8 \pm 0.11$ & - \\
\hline & Gentamycin standard & $20 \mathrm{mg} / \mathrm{ml}$ & 3.2 & 3.3 & 3.2 & 2.9 \\
\hline
\end{tabular}

Each value represents the mean \pm SD; EC- Escherechia coli; EF- Enterococcus faecalis; BS- Bacillus subtilis; SA-Staphylococcus aureus 
Table 2: Antifungal activity of root, callus and fruit extracts on fungus, Candida albicans

\begin{tabular}{|l|l|l|l|}
\hline Method & Methanolic Extracts & Concentration $(\boldsymbol{\mu l})$ & zone of inhibition $(\mathbf{c m})$ \\
\hline \multirow{4}{*}{$\begin{array}{l}\text { Agar-well } \\
\text { Diffusion method }\end{array}$} & \multirow{2}{*}{ Root } & 50 & - \\
\cline { 2 - 4 } & \multirow{2}{*}{ Callus } & 100 & - \\
\cline { 2 - 4 } & \multirow{2}{*}{ Fruit } & 50 & - \\
\cline { 2 - 4 } & & 100 & $1.1 \pm 0.07$ \\
\cline { 2 - 4 } & Clotrimazole (Standard antifungal agent) & 50 & - \\
\cline { 2 - 4 } & & 100 & $1.3 \pm 0.09$ \\
\hline
\end{tabular}

Each value represents the mean \pm SD

\section{Antibacterial activity}

Of the four bacterial strains employed fruit extract was comparatively more effective against all the three strains except $S$. aureus. All the extracts shown almost similar inhibitory effect against E. faecalis and B. subtilis. Fruit extract showed much higher zone of inhibition against $E$. faecalis than the standard antibacterial Gentamycin. Only callus extract showed some inhibitory against $S$. aureus that too at higher concentration. Root and callus extract has no effect on E.coli.

\section{Antifungal activity}

It is clear from the Table 2 that root has no inhibitory effect on $C$. albicans. On increasing concentration callus and fruit extracts shown inhibitory activity on comparison with the antifungal standard.

\section{Discussion}

Medicinal plants used in traditional medicines are potentially effective antimicrobial agents. Agar well diffusion method was employed inorder to compare the antimicrobial efficacy of extracts. Both antibacterial and antifungal activity was assayed by measuring the diameter of zone of inhibition. The antimicrobial and antifungal activities of the extracts increased linearity with increase in concentration of extracts. Except $E$. coli all other bacterial strains were gram positive. The extracts were effective at least at higher concentrations against all bacterial strains except against $S$. aureus for which only callus extract in its higher concentration $(100 \mu \mathrm{l})$ showed a positive result. Only the fruit extract exhibited activity against E. coli. It was quite interesting that against E. faecalis fruit extracts inhibiting activity exceeded that of the standard antibiotic Gentamycin. Root extract showed no activity against $E$. faecalis, but callus extracts showed activity on increasing concentration. Although there is considerable variation in the concentration range and diameter of zone of inhibition, it was against B. subtilis all extracts showed activity of which fruit extracts showed the maximum. Root extracts were not effective against any of the bacterial strains except against $B$. subtilis. Coming to antifungal activity which was tested against $C$. albicans that too by Agar well diffusion assay showed that root extract showed no activity while both callus and fruit extract showed significant activity on increasing concentration with reference to the standard antifungal Clotrimazole used.

Present study clearly indicates that all the extracts possess antimicrobial activity. Study must be extended further to other bacterial and fungal species and on increasing concentration of samples. The remarkable point of the present study is the antimicrobial efficiency of callus extracts. It is clear that $M$. smilacifolium is much promising as a medicinal plant which could serve as a good candidate in pharmaceutical industry. Higher antimicrobial activity of fruit extract against $E$. faecalis strictly proves its efficiency and presence of some specific phytoconstituent responsible which should be traced out and characterized. But the major limitation of this plant is its low flowering and fruiting habit which must be traced out. The present study surely forms a basic for further studies to investigate the bioactive compounds, their isolation and structure elucidation.

\section{Acknowledgement}

The authors wish to thank University of Kerala for providing the facilities and financial support for carrying out the work

\section{References}

Franzyk H, Jensen SR and Olsen CE (2001) Iridoid Glucosides from Myxopyrum smilacifolium. J. Nat. Prod.64: 632633. DOI: $10.1021 / \mathrm{np} 000431 \mathrm{v}$

Gopalakrishnan S, Rajameena R and Vadivel E (2012) Antimicrobial activity of leaves of Myxopyrum serratulum A.W. Hill, Int. J. Pharm. Sci. Drug Res. 4(1): 31-34

Gopalakrishnan S, Rajameena R and Vadivel E (2012) Phytochemical and Pharmacognostical studies of leaves of Myxopyrum serratulum .A.W Hill. J. chem. pharm. res. 4(1):788-794.

National Committee for Clinical Laboratory Standards (1993). Performance Standards for Antimicrobial Disk Susceptibility Test Approved Standard M2-A5 NCCLS, Villanova, PA 5

Sandhya B, Thomas $\mathrm{S}$, Isabel $\mathrm{W}$ and Shenbagarathai $\mathrm{R}$ (2006) Ethnomedicinal plants used by valaiyan community of Piranmalai hills (Reserved forest), Tamil Nadu, India - A pilot study. Afr. J. Tradit. Complement. Altern. Med .3: 101-114. 
Sudharmini D and Ashalatha S Nair (2008) Antimicrobial Studies of Triterpenoid Fractions from Myxopyrum smilacifolium Blume.Ethnobotanical Leaflets 12: 912-15.

Vaidhyrathnam PS Warrier (1996) Indian medicinal plants- a compendium of 500 species. Arya vaidya sala Kottakkal 4: 88 .
Verpoorte R (1998) Chemodiversity and the Biological Role of Secondary metabolites, some thoughts for selecting plant material for drug development. Proc. Phytochem. Soc. Europe, Kluwer Publishers. 43: 11-24. 